\title{
Determinants of Short-Term Weight Gain Following Surgical Treatment for Craniopharyngioma in Adults
}

\author{
A Ram Hong, ${ }^{1}$ Jung Hee Kim, ${ }^{2,3}$ Seung Shin Park, ${ }^{2}$ Sung Hye Kong, ${ }^{2,3}$ Hyung Jin Choi, ${ }^{4}$ Yong Hwy Kim,${ }^{3,5}$ Chan Soo Shin ${ }^{2,3}$ \\ Department of Internal Medicine,' Chonnam National University Medical School, Gwangju, Korea \\ Department of Internal Medicine, ${ }^{2}$ Seoul National University College of Medicine, Seoul, Korea \\ Department of Pituitary Center, ${ }^{3}$ Seoul National University College of Medicine, Seoul, Korea \\ Department of Anatomy, ${ }^{4}$ Seoul National University College of Medicine, Seoul, Korea \\ Department of Neurosurgery, ${ }^{5}$ Seoul National University College of Medicine, Seoul, Korea
}

Objective : Craniopharyngiomas (CPs) are associated with hypothalamic damage that causes hypothalamic obesity, however, the mechanisms underlying CP-related postoperative weight gain remain debatable. This study aimed to elucidate whether the major determinant of postoperative weight gain in patients with $\mathrm{CP}$ is hypothalamic injury or steroid replacement therapy.

Methods : We included 48 adult patients with CP (age $\geq 18$ years) who underwent transsphenoidal surgery between 2010 and 2018 in a single tertiary center, and whose body weight was measured pre- and postoperatively ( $<120$ days after the surgery). We recruited 144 age- and body mass index-matched patients with non-functioning pituitary adenoma (NFPA) as controls.

Results : Patients with CP experienced greater postoperative weight gain than patients with NFPA ( $3.0 \pm 5.1 \mathrm{vs} .0 .1 \pm 3.6 \mathrm{~kg}, p<0.001)$. The prevalence of postoperative steroid use was significantly higher in patients with CP than in those with NFPA (89.6\% vs. 34.0\%, $p<0.001)$. Steroid replacement therapy and CP were associated with postoperative weight gain after adjusting for covariates in overall patients ( $p=0.032$ and 0.007 , respectively). In subgroup analysis with postoperative steroid users, weight gain was significantly greater in patients with CP ( $n=43,0.96 \pm 0.25 \mathrm{~kg} / \mathrm{month})$ than in patients with NFPA ( $n=49,0.26 \pm 0.23 \mathrm{~kg} / \mathrm{month})$ even after adjusting for the daily steroid dose $(p=0.048)$.

Conclusion : Patients with CP experience greater postoperative weight gain than those with NFPA. Hypothalamic damage itself as well as steroid replacement may contribute to the postoperative weight gain in patients with CP.

Key Words : Craniopharyngioma · Pituitary adenoma · Obesity · Surgery $\cdot$ Steroid.

\section{INTRODUCTION}

Craniopharyngioma (CP) is the most commonly noted tumor originating from the suprasellar region ${ }^{9,12}$. Despite being a rare and benign disease, $\mathrm{CP}$ frequently manifests as aggressive tumor growth with hypothalamic/pituitary involvement. In adult CP patients, the preferred treatment of choice is a total resection of the tumor by transcranial or transsphenoidal

- Received : March 16, $2021 \cdot$ Revised : May 26, $2021 ・$ Accepted : August 12, 2021

- Address for reprints : Yong Hwy Kim

Departments of Pituitary Center and Neurosurgery, Seoul National University Hospital, Seoul National University College of Medicine, 101 Daehak-ro, Jongno-gu, Seoul 03080, Korea

Tel : +82-2-2072-4062, Fax : +82-2-744-8459, E-mail : kimyh96@snu.ac.kr, ORCID : https://orcid.org/0000-0001-9009-4191

This is an Open Access article distributed under the terms of the Creative Commons Attribution Non-Commercial License (http://creativecommons.org/licenses/by-nc/4.0) which permits unrestricted non-commercial use, distribution, and reproduction in any medium, provided the original work is properly cited. 
surgery $^{2,6)}$. Postoperatively, most CP patients experience pituitary hormone deficiency, which can be appropriately managed with hormone replacement therapy. Moreover, hypothalamic damage induces sleep disturbances, altered temperature regulation, visual impairment, and thirst sensation ${ }^{22)}$.

A more critical postoperative concern in CP patients is hypothalamic obesity (HO), which is observed in approximately $50 \%$ of all patients ${ }^{3,20)}$. HO usually occurs during the first 1 year following surgery, however, it also occurs at diagnosis (i.e., before surgery) in patients with CP. HO is the leading cause of severe atherosclerotic cardiovascular disease, type 2 diabetes, and metabolic syndrome, and confers a three- to five-fold higher mortality risk than that in the general population. Furthermore, HO results in impaired quality of life, which can be a permanent sequela in these patients ${ }^{5}$.

The pathogenesis of $\mathrm{HO}$ in postoperative $\mathrm{CP}$ patients is not completely understood. In addition, there is controversy regarding the use of the term, "hypothalamic obesity", to indicate postoperative weight gain in CP patients because it is unclear whether the main determinant of the postoperative weight gain is hypothalamic damage. $\mathrm{HO}$ also occurs in $\mathrm{CP}$ patients who seems not to have apparently damaged hypothalamus after surgical resection. In that case, excessive or long-term postoperative steroid replacement therapy which is commonly administered to CP patients may be the main con- tributor to the postoperative weight gain.

Therefore, we aimed to ascertain whether the main determinant of postoperative weight gain in CP patients is hypothalamic injury or steroid hormone replacement. The primary objective was to investigate the relationship between postoperative body weight change and steroid replacement therapy in CP patients. The secondary objective was to compare these associations with those noted in patients with postoperative non-functioning pituitary adenoma (NFPA).

\section{MATERIALS AND METHODS}

The study was approved by the Institutional Review Board of Seoul National University Hospital and was conducted according to the Declaration of Helsinki (IRB No. 1710-096895). Informed consent was waived due to the retrospective nature of the study.

\section{Study population}

This retrospective study was conducted at the Seoul National University Hospital. Adult patients (age $\geq 18$ years) with newly diagnosed with CP or NFPA who had undergone transsphenoidal gross total resection (GTR) between May 2010 and May 2018 were eligible in the study. Both CP and NFPA were

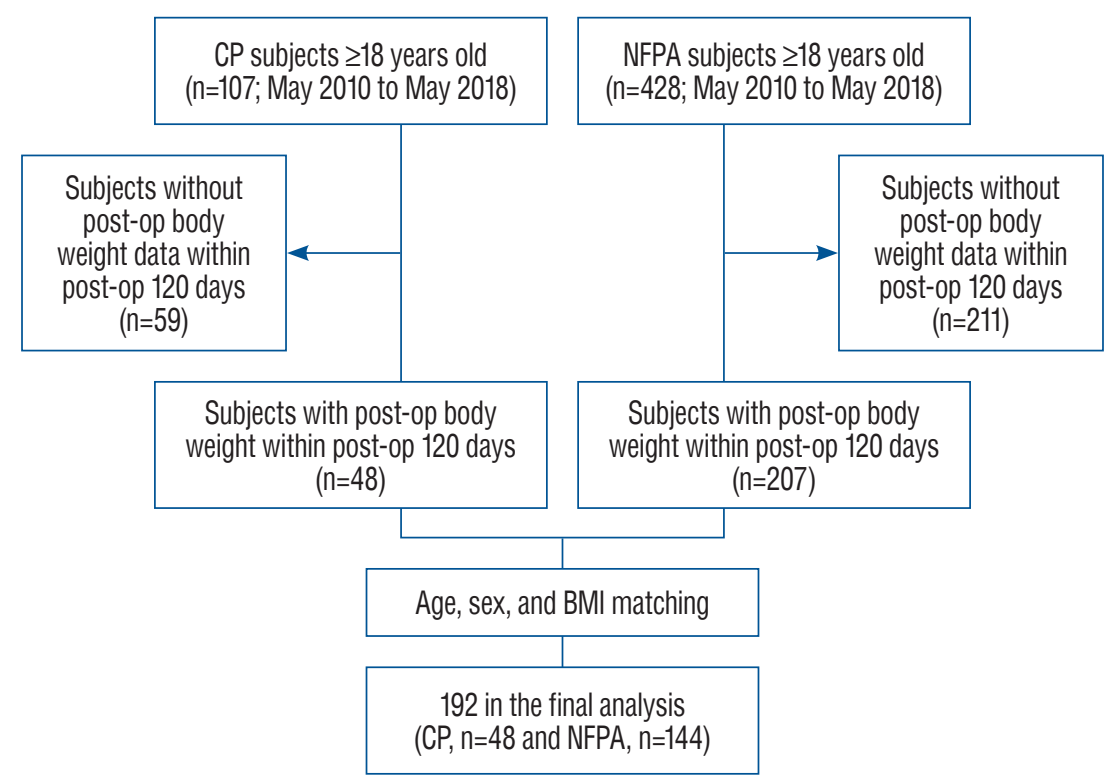

Fig. 1. Flow diagram of the study subjects. CP : craniopharyngioma, NFPA : non-functioning pituitary adenoma, post-op : post-operative, BMI : body mass index. 
diagnosed on the basis of the postoperative pathologic findings. GTR was determined according to total tumor removal based on the surgeon's view, and the detection of no residual tumor on immediate postoperative magnetic resonance imaging (MRI). Through a chart review of the medical records, we initially identified 107 patients with CP and 428 patients with NFPA, and then excluded 59 patients with CP and 211 patients with NFPA with missing data for body weight within 120 days after the surgery. Furthermore, among NFPA patients, we selected 144 patients whose age, sex, and body mass index (BMI) were matched to those with CP. Thus, 48 patients with CP and 144 patients with NFPA, who were considered controls, were included in the final analysis (Fig. 1).

Height and body weight were measured preoperatively, and BMI was calculated as weight divided by height squared $\left(\mathrm{kg} / \mathrm{m}^{2}\right)$. The postoperative body weight was measured within 120 days after the surgery, and the duration of follow-up was determined by the interval between the preoperative and postoperative body weight measurements. Prevalence of preoperative comorbidities including diabetes mellitus, hypertension, cardiovascular disease (i.e., angina and myocardial infarction), and cerebrovascular disease (i.e., ischemic stroke) was evaluated. We obtained data on postoperative steroid hormone replacement from the medical records. To adjust for differences in the glucocorticoid potency among steroid regimens, we calculated the equivalent steroid dose with hydrocortisone as the standard reference. Furthermore, we reviewed the preoperative hypothalamic symptoms, including psychosocial problems, hyperphagia, sleep abnormalities, and decreased energy expenditure.

\section{Hormone function assessment}

The morning basal hormone and dynamic function tests were conducted to assess hormone deficiency in all patients, both preoperatively and at 3 months after surgery. We measured the levels of growth hormone, insulin-like growth factor-I, adrenocorticotropic hormone (ACTH), serum cortisol, free T4, thyroid-stimulating hormone (TSH), luteinizing hormone (LH), follicle-stimulating hormone (FSH), estradiol or total testosterone, and serum prolactin by using radioimmunoassay and immunoradiometric assay, in venous blood samples collected between $8 \mathrm{AM}$ and $10 \mathrm{AM}$. ACTH deficiency was defined as a peak cortisol level $\leq 18 \mu \mathrm{g} / \mathrm{dL}$ after a short Synacthen test, or a low morning cortisol level $(<5 \mu \mathrm{g} / \mathrm{dL})$ with a low-to-normal ACTH level (10-65 pg/mL). TSH deficiency was defined as a low free T4 level $(<0.70 \mathrm{ng} / \mathrm{dL})$ and a low-tonormal TSH level (reference range, 0.4-4.1 uIU/mL). Gonadotropin deficiency was determined as oligomenorrhea associated with estradiol levels $<50 \mathrm{pg} / \mathrm{mL}$ and normal or low FSH/ LH levels in premenopausal women, and an FSH level $<30$ $\mathrm{mIU} / \mathrm{mL}$ in postmenopausal women. In men, low testosterone levels $(<2.8 \mathrm{ng} / \mathrm{mL})$ and low-to-normal FSH/LH levels were defined as gonadotropin deficiency. Panhypopituitarism was defined as complete or partial deficiency in anterior pituitary hormones and includes adrenal insufficiency, hypothyroidism, hypogonadism, and growth hormone deficiency.

\section{Preoperative Puget classification for $\mathrm{CP}$}

MRI of the sellar area was performed for all patients preoperatively. In CP, the grading of the hypothalamic involvement was classified according to Puget classification ${ }^{16)}$, as follows : grade 0 , no hypothalamic involvement; grade 1, tumor abutting or displacing the hypothalamus; and grade 2, hypothalamic involvement (the hypothalamus is no longer identifiable).

\section{Statistical analysis}

Data are expressed as mean \pm standard deviation for continuous variables and number (\%) for categorical variables. Comparisons between two groups were performed using the student t-test for numeric variables and the chi-square test for categorical variables. Comparisons between three groups were performed using analysis of variance and analysis of covariance after adjusting for confounders. The Bonferroni correction was adopted as a post hoc analysis to account for the multiple testing issues. A $p$-value $<0.05$ was considered statistically significant. All statistical analyses were performed using SPSS Statistics for Windows (version 25; IBM Corp., Armonk, NY, USA).

\section{RESULTS}

The baseline characteristics of the study subjects are shown in Table 1. The mean age and the preoperative BMI of overall patients were $51.3 \pm 14.4$ years and $25.0 \pm 3.6 \mathrm{~kg} / \mathrm{m}^{2}$, respectively. The mean follow-up duration was 91.2 days. CP patients had higher prevalence of diabetes mellitus than those with NFPA 
$(p=0.045)$. The tumor volume was higher in patients with NFPA than in those with CP $\left(11.99 \pm 18.55\right.$ vs. $6.29 \pm 7.80 \mathrm{~cm}^{3}$, $p=0.042$ ). However, the degree of pre- and postoperative hormone deficiency was greater in patients with CP than in those with NFPA, which indicates a higher prevalence of panhypo- pituitarism in patients with CP (both $p<0.001$ ). In postoperative CP patients, the prevalence of hormone deficiency was $85.4 \%$ for growth hormone, $85.4 \%$ for gonadotropin, $87.5 \%$ for thyroid hormone, and $87.5 \%$ for cortisol. While in postoperative NFPA patients, the prevalence of hormone deficiency

Table 1. Baseline characteristics of subjects with CP and NFPA

\begin{tabular}{|c|c|c|c|c|}
\hline Variable & Total $(n=192)$ & $\mathrm{CP}(\mathrm{n}=48)$ & NFPA $(n=144)$ & $p$-value \\
\hline Age (years) & $51.3 \pm 14.4$ & $48.8 \pm 13.0$ & $52.1 \pm 14.7$ & 0.169 \\
\hline Male & $92(47.9)$ & $27(56.2)$ & $65(45.1)$ & 0.182 \\
\hline Height (cm) & $163.8 \pm 8.6$ & $163.4 \pm 9.3$ & $164.0 \pm 8.4$ & 0.675 \\
\hline Preoperative body weight (kg) & $67.4 \pm 12.4$ & $67.3 \pm 11.8$ & $67.4 \pm 12.6$ & 0.971 \\
\hline Preoperative BMI $\left(\mathrm{kg} / \mathrm{m}^{2}\right)$ & $25.0 \pm 3.6$ & $25.1 \pm 3.5$ & $25.0 \pm 3.7$ & 0.759 \\
\hline Preoperative obesity & $88(45.8)$ & $22(45.8)$ & $66(45.8)$ & 1.000 \\
\hline Postoperative body weight (kg) & $68.2 \pm 12.5$ & $70.2 \pm 11.8$ & $67.5 \pm 12.8$ & 0.190 \\
\hline Postoperative BMI (kg/m²) & $25.3 \pm 3.6$ & $26.2 \pm 3.1$ & $25.0 \pm 3.7$ & 0.042 \\
\hline Postoperative obesity & $91(47.4)$ & $30(62.5)$ & $61(42.4)$ & 0.016 \\
\hline Body weight change (kg) & $0.8 \pm 4.2$ & $3.0 \pm 5.1$ & $0.1 \pm 3.6$ & 0.001 \\
\hline Weight change per month (kg/month) & $0.2 \pm 1.5$ & $1.0 \pm 1.8$ & $0.0 \pm 1.3$ & $<0.001$ \\
\hline$\%$ body weight change & $1.1 \pm 5.9$ & $4.1 \pm 6.8$ & $0.0 \pm 5.2$ & $<0.001$ \\
\hline Diabetes mellitus & $18(9.4)$ & $8(16.7)$ & $10(6.9)$ & 0.045 \\
\hline Hypertension & $37(19.3)$ & $11(22.9)$ & $26(18.1)$ & 0.460 \\
\hline Cardiovascular disease & $3(1.6)$ & $0(0.0)$ & $3(2.1)$ & 0.313 \\
\hline Cerebrovascular disease & $1(0.5)$ & $1(2.1)$ & $0(0.0)$ & 0.082 \\
\hline Follow-up duration (days) & $91.2 \pm 22.9$ & $90.9 \pm 16.6$ & $91.4 \pm 24.7$ & 0.896 \\
\hline Postoperative steroid user & $92(47.9)$ & $43(89.6)$ & $49(34.0)$ & $<0.001$ \\
\hline Daily steroid dose (mg/day) & $7.4 \pm 8.8$ & $15.0 \pm 7.6$ & $4.9 \pm 7.7$ & $<0.001$ \\
\hline Cumulative steroid dose (mg) & $664.4 \pm 786.0$ & $1349.9 \pm 676.9$ & $435.9 \pm 681.5$ & $<0.001$ \\
\hline Tumor volume $\left(\mathrm{cm}^{3}\right)$ & $10.58 \pm 16.72$ & $6.29 \pm 7.80$ & $11.99 \pm 18.55$ & 0.042 \\
\hline Number of preoperative hormone deficiency & & & & $<0.001$ \\
\hline 0 & $44(22.9)$ & $15(31.3)$ & $29(20.1)$ & \\
\hline 1 & $51(26.6)$ & $8(16.7)$ & $43(29.9)$ & \\
\hline 2 & $37(19.3)$ & $5(10.4)$ & $32(22.2)$ & \\
\hline 3 & $25(13.0)$ & $1(2.1)$ & $24(16.7)$ & \\
\hline 4 & $35(18.2)$ & 19 (39.6) & $16(11.1)$ & \\
\hline Number of postoperative hormone deficiency & & & & $<0.001$ \\
\hline 0 & $28(14.6)$ & $5(10.4)$ & $23(16.0)$ & \\
\hline 1 & $51(26.6)$ & $2(4.2)$ & $49(34.0)$ & \\
\hline 2 & $36(18.8)$ & $0(0.0)$ & $36(25.0)$ & \\
\hline 3 & $20(10.4)$ & $0(0.0)$ & $20(13.9)$ & \\
\hline 4 & $57(29.7)$ & $41(85.4)$ & $16(11.1)$ & \\
\hline
\end{tabular}

Values are presented as mean \pm standard deviation or number (\%). CP : craniopharyngioma, NFPA : non-functioning pituitary adenoma, BMI : body mass index 
was $52.1 \%$ for growth hormone, $54.2 \%$ for gonadotropin, $25.7 \%$ for thyroid hormone, and $23.6 \%$ for cortisol. Patients with $\mathrm{CP}$ were more frequently prescribed steroid hormone replacement after surgery than those with NFPA (89.6\% vs. $34.0 \%, p<0.001)$. There was no significant between-group difference in the postoperative body weight $(p=0.190)$. However, $\mathrm{CP}$ patients experienced greater postoperative weight gain than NFPA patients (3.0 \pm 5.1 vs. $0.1 \pm 3.6 \mathrm{~kg}, p=0.001)$. Postoperative BMI was also significantly higher in patients with $\mathrm{CP}$ than those with NFPA ( $p=0.042)$. Interestingly, the prevalence of obesity (defined as BMI $\geq 25 \mathrm{~kg} / \mathrm{m}^{2}$ based on the definition of obesity for Asians ${ }^{23)}$ ) was similar between CP and NFPA patients before surgery ( $45.8 \%$ vs. $45.8 \%, p=1.000$ ), however, higher in patients with CP than those with NFPA after surgery $(62.5 \%$ vs. $42.4 \%, p=0.016)$.

We performed subgroup analysis of the patients with postoperative steroid use (Table 2). Patients with CP showed greater postoperative weight gain than those with NFPA (3.0 \pm 5.2 vs. $0.9 \pm 4.6 \mathrm{~kg}, p=0.039$ ). Moreover, the weight change per month and percentage body weight change were significantly greater in patients with CP than in those with NFPA $(p=0.027$ and $p=0.029$, respectively). The cumulative steroid dose was significantly higher in the CP groups (1506.9 \pm 520.1 vs. 1281.1 $\pm 527.4 \mathrm{mg}, p=0.042$ ), although there was no significant between-group difference in the daily steroid dose $(16.7 \pm 5.9 \mathrm{mg}$ in CP and 14.4 $\pm 5.9 \mathrm{mg}$ in NFPA, $p=0.059)$. Postoperative hor-

Table 2. Comparison of characteristics between subjects with CP and NFPA only in postoperative steroid users

\begin{tabular}{|c|c|c|c|c|}
\hline Variable & Total $(n=92)$ & $C P(n=43)$ & NFPA $(n=49)$ & $p$-value \\
\hline Age (years) & $51.3 \pm 13.4$ & $48.6 \pm 13.5$ & $53.6 \pm 13.0$ & 0.074 \\
\hline Male & $54(58.7)$ & $25(58.1)$ & $29(59.2)$ & 0.919 \\
\hline Height (cm) & $164.6 \pm 9.1$ & $163.4 \pm 9.6$ & $165.5 \pm 8.6$ & 0.276 \\
\hline Preoperative body weight (kg) & $69.2 \pm 12.2$ & $67.5 \pm 12.2$ & $70.7 \pm 12.2$ & 0.218 \\
\hline Preoperative BMI $\left(\mathrm{kg} / \mathrm{m}^{2}\right)$ & $25.5 \pm 3.8$ & $25.2 \pm 3.7$ & $25.8 \pm 4.0$ & 0.498 \\
\hline Postoperative body weight (kg) & $71.1 \pm 12.1$ & $70.6 \pm 12.2$ & $71.6 \pm 12.1$ & 0.693 \\
\hline Body weight change $(\mathrm{kg})$ & $1.9 \pm 5.0$ & $3.0 \pm 5.2$ & $0.9 \pm 4.6$ & 0.039 \\
\hline Weight change per month (kg/month) & $0.6 \pm 1.7$ & $1.0 \pm 1.8$ & $0.2 \pm 1.6$ & 0.027 \\
\hline$\%$ body weight change & $2.5 \pm 6.8$ & $4.2 \pm 7.0$ & $1.1 \pm 6.3$ & 0.029 \\
\hline Follow-up duration (days) & $91.3 \pm 19.1$ & $91.1 \pm 15.0$ & $91.4 \pm 22.2$ & 0.932 \\
\hline Daily steroid dose (mg/day) & $15.5 \pm 6.0$ & $16.7 \pm 5.9$ & $14.4 \pm 5.9$ & 0.059 \\
\hline Cumulative steroid dose (mg) & $1386.6 \pm 533.3$ & $1506.9 \pm 520.1$ & $1281.1 \pm 527.4$ & 0.042 \\
\hline Tumor volume $\left(\mathrm{cm}^{3}\right)$ & $9.77 \pm 9.81$ & $6.72 \pm 8.02$ & $12.45 \pm 10.52$ & 0.005 \\
\hline Number of preoperative hormone deficiency & & & & 0.005 \\
\hline 0 & $16(17.4)$ & $11(25.6)$ & $5(10.2)$ & \\
\hline 1 & $15(16.3)$ & $7(16.3)$ & $8(16.3)$ & \\
\hline 2 & $15(16.3)$ & $5(11.6)$ & $10(20.4)$ & \\
\hline 3 & $14(15.2)$ & $1(2.3)$ & $13(26.5)$ & \\
\hline 4 & $32(34.8)$ & $19(44.2)$ & $13(26.5)$ & \\
\hline Number of postoperative hormone deficiency & & & & $<0.001$ \\
\hline 0 & $4(4.3)$ & $2(4.7)$ & $2(4.1)$ & \\
\hline 1 & $9(9.8)$ & $2(4.7)$ & $7(14.3)$ & \\
\hline 2 & $12(13.0)$ & $0(0.0)$ & $12(24.5)$ & \\
\hline 3 & $14(15.2)$ & $0(0.0)$ & $14(28.6)$ & \\
\hline 4 & $53(57.6)$ & $39(90.7)$ & $14(28.6)$ & \\
\hline
\end{tabular}

Values are presented as mean \pm standard deviation or number (\%). CP : craniopharyngioma, NFPA : non-functioning pituitary adenoma, BMI : body mass index 
Table 3. Comparison of characteristics of all subjects according to the daily steroid dose

\begin{tabular}{|c|c|c|c|c|}
\hline Variable & $0 \mathrm{mg}(\mathrm{n}=100)$ & $5-10 \mathrm{mg}(\mathrm{n}=27)$ & $\geq 15 \mathrm{mg}(\mathrm{n}=65)$ & $p$-value for trend* \\
\hline Age (years) & $51.3 \pm 15.2$ & $53.4 \pm 12.3$ & $50.4 \pm 13.9$ & 0.667 \\
\hline Male & $38(38.0)$ & $13(48.1)$ & $41(63.1)$ & $0.007^{\dagger}$ \\
\hline Height $(\mathrm{cm})$ & $163.2 \pm 8.2$ & $162.7 \pm 8.1$ & $165.3 \pm 9.5$ & 0.229 \\
\hline Preoperative body weight (kg) & $65.6 \pm 12.3$ & $67.5 \pm 11.5$ & $69.9 \pm 12.5$ & 0.092 \\
\hline Preoperative BMI $\left(\mathrm{kg} / \mathrm{m}^{2}\right)$ & $24.5 \pm 3.4$ & $25.6 \pm 4.6$ & $25.5 \pm 3.5$ & 0.180 \\
\hline Postoperative body weight (kg) & $65.5 \pm 12.4$ & $68.7 \pm 11.0$ & $72.1 \pm 12.5^{\ddagger}$ & 0.004 \\
\hline Body weight change $(\mathrm{kg})$ & $-0.1 \pm 3.0$ & $1.2 \pm 4.6$ & $2.2 \pm 5.2^{\ddagger}$ & 0.002 \\
\hline Weight change per month (kg/month) & $-0.1 \pm 1.1$ & $0.4 \pm 1.5$ & $0.7 \pm 1.9^{\ddagger}$ & 0.002 \\
\hline$\%$ body weight change & $-0.3 \pm 4.5$ & $1.7 \pm 6.8$ & $2.9 \pm 6.8^{\ddagger}$ & 0.002 \\
\hline Follow-up duration (days) & $91.2 \pm 26.1$ & $93.7 \pm 17.7$ & $90.3 \pm 19.6$ & 0.811 \\
\hline $\mathrm{CP}$ & $5(5.0)$ & $6(22.2)$ & $37(56.9)$ & $<0.001^{\dagger}$ \\
\hline Daily steroid dose (mg/day) & $0.0 \pm 0.0$ & $9.4 \pm 1.6^{\ddagger}$ & $18.0 \pm 5.3^{\ddagger}$ & $<0.001$ \\
\hline Cumulative steroid dose (mg) & $0.0 \pm 0.0$ & $893.7 \pm 245.2^{\ddagger}$ & $1591.4 \pm 484.6^{\ddagger}$ & $<0.001$ \\
\hline Tumor volume $\left(\mathrm{cm}^{3}\right)$ & $11.34 \pm 21.25$ & $11.53 \pm 9.76$ & $9.04 \pm 9.82$ & 0.660 \\
\hline Number of preoperative hormone deficiency & & & & $<0.001^{\dagger}$ \\
\hline 0 & $28(28.0)$ & $4(14.8)$ & $12(18.5)$ & \\
\hline 1 & $36(36.0)$ & $6(22.2)$ & $9(13.8)$ & \\
\hline 2 & $22(22.0)$ & $7(25.9)$ & $8(12.3)$ & \\
\hline 3 & $11(11.0)$ & $5(18.5)$ & $9(13.8)$ & \\
\hline 4 & $3(3.0)$ & $5(18.5)$ & $27(41.5)$ & \\
\hline Number of postoperative hormone deficiency & & & & $<0.001^{\dagger}$ \\
\hline 0 & $24(24.0)$ & $2(7.4)$ & $2(3.1)$ & \\
\hline 1 & $42(42.0)$ & $4(14.8)$ & $5(7.7)$ & \\
\hline 2 & $24(24.0)$ & $5(18.5)$ & $7(10.8)$ & \\
\hline 3 & $6(6.0)$ & $4(14.8)$ & $10(15.4)$ & \\
\hline 4 & $4(4.0)$ & $12(44.4)$ & $41(63.1)$ & \\
\hline
\end{tabular}

Values are presented as mean \pm standard deviation or number (\%). ${ }^{*} p$-values for these trends were generated by simple linear regression analysis. ${ }^{\dagger} p$ values were generated by chi-square test. ${ }^{\ddagger} p<0.05$ vs. 0 mg in the post-hoc analysis. BMl : body mass index, CP : craniopharyngioma
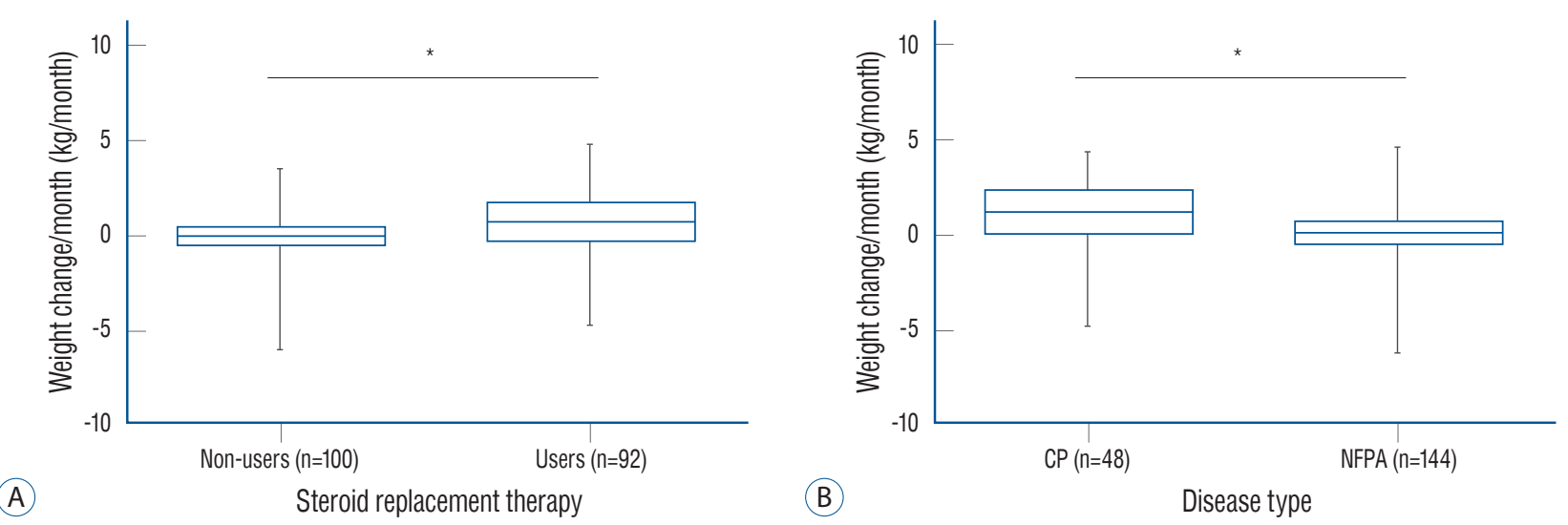

Fig. 2. Box and whisker plot of weight change per month in all subjects according to the (A) steroid replacement therapy after adjusting for age, sex, body mass index (BMI), and disease type and (B) disease type after adjusting for age, sex, BMI, and steroid replacement therapy. Data are expressed as median (range). ${ }^{*} p<0.05$. CP : craniopharyngioma, NFPA : non-functioning pituitary adenoma. 

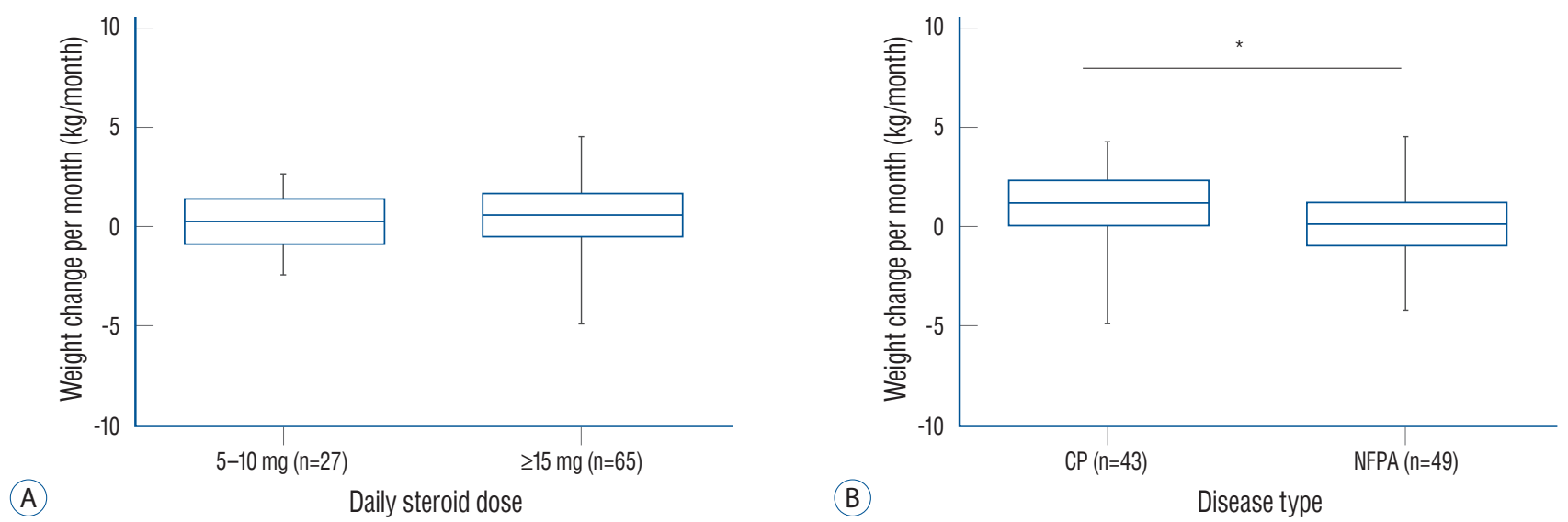

Fig. 3. Box and whisker plot of weight change per month only in steroid users according to the (A) daily steroid dose after adjusting for age, sex, body mass index (BMI), and disease type and (B) disease type after adjusting for age, sex, BMI, and daily steroid dose. Data are expressed as median (range). ${ }^{*} p<0.05$. CP : craniopharyngioma, NFPA : non-functioning pituitary adenoma.

mone deficiency was more prevalent in CP patients than in NFPA patients.

To investigate the dose-dependent relationship between steroid replacement and postoperative weight gain, we stratified patients into three groups based on the daily hydrocortisone dose of $0,5-10$, and $\geq 15 \mathrm{mg}$. Although preoperative body weight did not differ between the three groups, postoperative body weight was significantly higher in the $\geq 15 \mathrm{mg}$ than in other two groups ( $p=0.004$ ). Body weight change, weight change per month, as well as percentage body weight change were highest in the $\geq 15 \mathrm{mg}$ group (all $p=0.002$ ). Patients with $\mathrm{CP}$ were more frequently prescribed a higher dose of daily hydrocortisone ( $p<0.001$; Table 3). Hydrocortisone was administered at a high dose only when postoperative infection (i.e., meningitis) was developed after surgery, and then at $15 \mathrm{mg} /$ day. Postoperative infection occurred in 27.1\% (13/48) of CP patients and $0.7 \%(1 / 144)$ of NFPA patients.

We analyzed weight change per month after adjusting for covariates to further investigate the relative effects of steroid replacement therapy and disease type (CP or NFPA) on postoperative weight gain. In all subjects, weight change per month was associated with steroid replacement therapy after adjusting for age, sex, preoperative BMI, and disease type ( $p=0.032$; Fig. 2A). CP patients showed greater weight change per month than NFPA patients after adjusting for age, sex, preoperative BMI, and steroid replacement therapy ( $p=0.007$; Fig. 2B). Similar analyses were performed in a subgroup with steroid users. Weight change per month did not differ according to the daily steroid dose after adjusting for covariates
( $p=0.925$; Fig. 3A). Interestingly, patients with CP showed greater weight change per month than those with NFPA even after adjusting for covariates, including daily steroid dose $(0.96$ \pm 0.25 vs. $0.26 \pm 0.23 \mathrm{~kg} /$ month, $p=0.048$; Fig. $3 \mathrm{~B}$ ).

To examine whether the hypothalamic damage affects the postoperative weight gain in $\mathrm{CP}$ patients, we analyzed the body weight change according to the preoperative Puget classification of the mass and the presence of preoperative hypothalamic symptoms. Preoperative tumor volume, prevalence of postoperative steroid use, and preoperative hypothalamic symptoms increased in accordance with the degree of hypothalamic involvement, which was assessed by Puget classification. However, the parameters of body weight change did not differ according to the degree of hypothalamic involvement (Supplementary Table 1). Furthermore, the presence of hypothalamic symptoms was not associated with postoperative body weight change (Supplementary Table 2).

\section{DISCUSSION}

The present study demonstrated that patients with CP exhibited greater postoperative weight gain than those with NFPA within 120 days after surgery. Patients with CP more frequently received postoperative steroid replacement therapy, and the daily steroid doses were higher than those in the patients with NFPA. However, regardless of the daily steroid dose, CP patients experienced greater postoperative weight gain. These findings suggest that steroid replacement therapy 
obviously affects postoperative weight gain in both $\mathrm{CP}$ and NFPA patients, however, in CP patients, the effect of tumorrelated hypothalamic injury is more robust than steroid replacement therapy in weight gain.

Unlike in simple obesity, postoperative CP patients show extremely high weight gain that is unrelentingly resistant to lifestyle modifications ${ }^{15)}$. Remarkable weight gain usually occurs during the first year following surgery ${ }^{17)}$. Because the majority of $\mathrm{CP}$ patients receive postoperative steroid replacement therapy for adrenal insufficiency, we initially investigated whether an excessive postoperative steroid replacement could be the main factor for weight gain in those patients. In the present study, postoperative steroid use was more prevalent among patients with $\mathrm{CP}$ than in those with NFPA, and the cumulative steroid doses were higher in CP patients. Our data indicate that steroid replacement is clearly an important factor for the occurrence of early postoperative weight gain in $\mathrm{CP}$ patients. This is in line with a previous report that dexamethasone replacement had short-term effects on postoperative weight gain in childhood-onset $\mathrm{CP}$ patients ${ }^{14}$. However, in the present study, the postoperative weight change was not associated with the daily steroid dose after adjusting for covariates. Notably, the daily doses of steroids were within the physiologic range (hydrocortisone $15 \mathrm{mg}$ ) ${ }^{7}$. It is difficult to clearly explain why steroid replacement therapy has a more robust effect on body weight in CP patients than NFPA patients. It may be attributed to a certain vulnerability of CP patients to steroid therapy or higher cumulative steroid doses. Consequently, long-term accumulation of these effects over time may lead to $\mathrm{HO}$ in CP patients.

We observed that the prevalence of panhypopituitarism in CP patients increased from $39.6 \%$ to $85.4 \%$ after surgery indicating pituitary stalk injury. The reason why other hormonal axis damages were common in $\mathrm{CP}$ patients is that most $\mathrm{CP}$ patients were of the retrochiasmatic type. Since long-term deficits of other pituitary hormones could affect the weight change, we defined the time point for evaluating the postoperative weight change as 3 months postoperatively. In the present study, immediate hormone replacement started when thyroid hormone deficiency was confirmed. Whereas, sex hormone and growth hormone replacements started 3 months after surgery. Therefore, the effect of pituitary hormone deficiency and replacement other than cortisol on body weight appears to be modest.

The hypothalamic injury induced by the tumor itself, sur- gery, and/or irradiation is indeed associated with HO. In the present study, we demonstrated that $\mathrm{CP}$ patients experienced significantly higher weight change per month than NFPA patients even after adjusting for the daily steroid dose. These findings suggest that hypothalamic damage is definitely a contributory factor for postoperative weight gain in $\mathrm{CP}$ patients. It is not clear whether the hypothalamus injury due to surgery or the hypothalamic injury due to the mass itself will have a stronger effect on the development of $\mathrm{HO}$ in $\mathrm{CP}$ patients. With respect to surgical procedure, we never performed the blunt dissection including curettage or two-suction technique to dissect the tumor from hypothalamus, but the microsurgical dissection with microdissectors for the GTR. The dissection was always started at the pituitary stalk of infundibulum after dissection and protection of superior hypophyseal artery and then continued along the tumor capsule with the meticulous attentions to prevent the premature rupture of tumor capsule. At the severe adhesive point, we dissected firstly the surrounding less adhesive tumor from hypothalamus and then finally dissected the most adhesive points. The details of our surgical techniques was described in our previous report ${ }^{4)}$. GTR was achieved in all patients. In the immediate postoperative MR taken within 24 hours showed the no further defect of hypothalamus tissue or stroke and postoperative Puget grade was deteriorated in none compared with preoperative Puget grade. In contrast, three patients with preoperative Puget grade 2 were classified to grade 0 after surgery. In addition, none experienced stroke within post-operative 120 days.

Regardless of the underlying cause, $\mathrm{HO}$ is closely related to hypothalamic dysfunctions that control energy metabolism homeostasis and appetite ${ }^{10}$. HO patients present with hyperphagia that results in excessive calorie intake ${ }^{19}$. Reduced energy expenditure is another major cause of $\mathrm{HO}$, and these patients show significantly decreased physical activity and basal metabolic rate ${ }^{1,8)}$. Moreover, the hypothalamic involvement by $\mathrm{CP}$ is related to decreased melatonin secretion, which leads to disturbances of the circadian rhythm and daytime sleepiness, that possibly leads to $\mathrm{HO}^{13}$.

Based on the hypothalamic nuclei that are affected, the pathophysiologic mechanisms and clinical manifestations that contribute to HO differ among patients. Theoretically, the ventromedial hypothalamus has been considered the most critical region in the development of $\mathrm{HO}^{19)}$. The ventromedial 
hypothalamus comprises the arcuate nucleus (ARC) and paraventricular nucleus. The ARC plays a major role in appetite regulation : the proopiomelanocortin neurons decrease appetite by contributing to a feeling of satiety, whereas agouti-related protein and neuropeptide Y contribute to increased appetite ${ }^{11)}$. Recently, the posterior hypothalamic nuclei, such as the dorsomedial nucleus (DMN), dorsal hypothalamic area nucleus, and ventromedial nucleus, have emerged as important factors in the pathogenesis of HO. These are key regulators of thermoregulation and locomotion that function by mediating leptin-induced energy expenditure and sympathetic activation ${ }^{21)}$. However, we observed no significant associations between postoperative weight gain and the degree of hypothalamic symptoms. Another study that used a novel hypothalamic lesion-scoring system showed that $\mathrm{HO}$ patients more frequently had an anterior and medial hypothalamic disruption. However, the most robust weight gain was observed in patients with lesions that affected the posterior hypothalamus, containing the DMN, and the dorsal hypothalamic area nucleus ${ }^{18)}$. Thus, to better understand the effects of hypothalamic damage on postoperative weight gain and obesity, a meticulous approach is needed for the specific hypothalamic region.

There are several limitations to be addressed for the study findings. First, we determined the degree of hypothalamic involvement by the Puget classification based on sella MRI findings. This classification provides a precise description of preand postoperative course in childhood-onset CP patients underwent surgical resection leading to treatment strategy. However, this approach is incapable of accurately representing the changes in the hypothalamic volume or specifying the regional damage to the hypothalamus, particularly the extent of damage to sites that are crucial for the regulation of energy metabolism. Second, we collected postoperative weight data that were measured within 120 days after the surgery, which is a short interval to represent a long-term sequela of HO. Moreover, we could not evaluate the postoperative changes in cardiometabolic parameters and related diseases, such as type 2 diabetes mellitus and cardiovascular disease, due to the retrospective design. Furthermore, we were unable to evaluate the postoperative eating behaviors and water balance. Thus, it is uncertain whether the weight gain was attributable to hyperphagia or low resting energy expenditure.

\section{CONCLUSION}

Taken together, postsurgical CP patients experience greater weight gain than those with NFPA during the first 120 days after surgery. Postoperative steroid replacement therapy plays a role in the weight gain of $\mathrm{CP}$ patients. Our findings suggest that hypothalamic damage itself as well as steroid replacement therapy seem to contribute to the postoperative weight gain in $\mathrm{CP}$ patients. However, there were no observable significant associations between postoperative weight gain and hypothalamic damage based on subjective symptoms and MRI. Therefore, further studies are needed to establish a direct link between hypothalamic damage and weight gain in $\mathrm{CP}$ patients.

\section{AUTHORS' DECLARATION}

\section{Conflicts of interest}

No potential conflict of interest relevant to this article was reported.

\section{Informed consent}

This type of study does not require informed consent.

\section{Author contributions}

Conceptualization : YHK, JHK; Data curation : ARH; Formal analysis : ARH, JHK, SSP; Methodology : ARH, SSP; Project administration : YHK, JHK; Visualization : ARH, JHK; Writing - original draft : ARH; Writing - review \& editing: YHK, ARH, JHK, SSP, SHK, HJC, CSS

\section{Data sharing}

None

\section{Preprint}

None

\section{ORCID}
A Ram Hong
https://orcid.org/0000-0002-2494-9902
Jung Hee Kim
https://orcid.org/0000-0003-1932-0234
Seung Shin Park 
Sung Hye Kong https://orcid.org/0000-0002-8791-0909

Hyung Jin Choi https://orcid.org/0000-0003-0593-6978

Yong Hwy Kim https://orcid.org/0000-0001-9009-4191

Chan Soo Shin https://orcid.org/0000-0002-5829-4465

\section{- Supplementary materials}

The online-only data supplement is available with this article at https://doi.org/10.3340/jkns.2021.0067.

\section{References}

1. Bomer I, Saure C, Caminiti C, Ramos JG, Zuccaro G, Brea M, et al. : Comparison of energy expenditure, body composition, metabolic disorders, and energy intake between obese children with a history of craniopharyngioma and children with multifactorial obesity. J Pediatr Endocrinol Metab 28 : 1305-1312, 2015

2. Buchfelder $M$, Schlaffer $S M$, Lin $F$, Kleindienst $A$ : Surgery for craniopharyngioma. Pituitary $16: 18-25,2013$

3. Cohen $M$, Guger $S$, Hamilton I : Long term sequelae of pediatric craniopharyngioma - literature review and 20 years of experience. Front Endocrinol (Lausanne) $2: 81,2011$

4. Dho YS, Kim YH, Se YB, Han DH, Kim JH, Park CK, et al. : Endoscopic endonasal approach for craniopharyngioma: the importance of the relationship between pituitary stalk and tumor. J Neurosurg 129 : 611619,2018

5. Erfurth EM, Holmer $H_{1}$ Fjalldal SB : Mortality and morbidity in adult craniopharyngioma. Pituitary $16:$ 46-55, 2013

6. Fahlbusch R, Honegger J, Paulus W, Huk W, Buchfelder M : Surgical treatment of craniopharyngiomas: experience with 168 patients. J Neurosurg $90:$ :237-250, 1999

7. Fleseriu M, Hashim IA, Karavitaki N, Melmed S, Murad MH, Salvatori R, et al. : Hormonal replacement in hypopituitarism in adults: an endocrine society clinical practice guideline. J Clin Endocrinol Metab 101 : 3888-3921, 2016

8. Harz KJ, Müller HL, Waldeck E, Pudel V, Roth C : Obesity in patients with craniopharyngioma: assessment of food intake and movement counts indicating physical activity. J Clin Endocrinol Metab 88 : 5227-5231, 2003

9. Karavitaki N, Brufani C, Warner JT, Adams CB, Richards P, Ansorge O, et al. : Craniopharyngiomas in children and adults: systematic analysis of 121 cases with long-term follow-up. Clin Endocrinol (0xf) 62 : 397409, 2005
10. Lee $\mathrm{M}$, Korner J : Review of physiology, clinical manifestations, and management of hypothalamic obesity in humans. Pituitary $12: 87-95$, 2009

11. Morton GJ, Cummings DE, Baskin DG, Barsh GS, Schwartz MW : Central nervous system control of food intake and body weight. Nature 443 : 289-295, 2006

12. Müller HL : Craniopharyngioma. Endocr Rev 35 : 513-543, 2014

13. Müller HL, Handwerker $G$, Wollny B, Faldum A, Sörensen $N$ : Melatonin secretion and increased daytime sleepiness in childhood craniopharyngioma patients. J Clin Endocrinol Metab 87 : 3993-3996, 2002

14. Müller HL, Heinrich M, Bueb K, Etavard-Gorris N, Gebhardt U, Kolb R, et al. : Perioperative dexamethasone treatment in childhood craniopharyngioma--influence on short-term and long-term weight gain. Exp Clin Endocrinol Diabetes 111 : 330-334, 2003

15. Ni W, Shi $X$ : Interventions for the treatment of craniopharyngiomarelated hypothalamic obesity: a systematic review. World Neurosurg 118 : e59-e71, 2018

16. Puget S, Garnett M, Wray A, Grill J, Habrand JL, Bodaert N, et al. : Pediatric craniopharyngiomas: classification and treatment according to the degree of hypothalamic involvement. J Neurosurg 106(1 Suppl) : 3-12, 2007

17. Roth $\mathrm{CL}$ : Hypothalamic obesity in craniopharyngioma patients: disturbed energy homeostasis related to extent of hypothalamic damage and its implication for obesity intervention. J Clin Med 4 : 1774-1797, 2015

18. Roth $\mathrm{CL}$, Eslamy $\mathrm{H}$, Werny $\mathrm{D}$, Elfers $\mathrm{C}$, Shaffer $\mathrm{ML}$, Pihoker $\mathrm{C}$, et al. : Semiquantitative analysis of hypothalamic damage on MRI predicts risk for hypothalamic obesity. Obesity (Silver Spring) 23 : 1226-1233, 2015

19. Seong J, Kang JY, Sun JS, Kim KW : Hypothalamic inflammation and obesity: a mechanistic review. Arch Pharm Res 42 : 383-392, 2019

20. Sterkenburg AS, Hoffmann A, Gebhardt U, Warmuth-Metz M, Daubenbüchel AM, Müller HL : Survival, hypothalamic obesity, and neuropsychological/psychosocial status after childhood-onset craniopharyngioma: newly reported long-term outcomes. Neuro Oncol 17 : 10291038, 2015

21. van Swieten MM, Pandit $R$, Adan RA, van der Plasse $G$ : The neuroanatomical function of leptin in the hypothalamus. J Chem Neuroanat 61-62 : 207-220, 2014

22. Wijnen $M$, van den Heuvel-Eibrink MM, Janssen JAMJL, CatsmanBerrevoets CE, Michiels EMC, van Veelen-Vincent MC, et al. : Very longterm sequelae of craniopharyngioma. Eur J Endocrinol 176 : 755-767, 2017

23. World Health Organization : The Asia-Pacific perspective: redefining obesity and its treatment. Available at : https://apps.who.int/ iris/bitstream/handle/10665/206936/0957708211_eng.pdf 